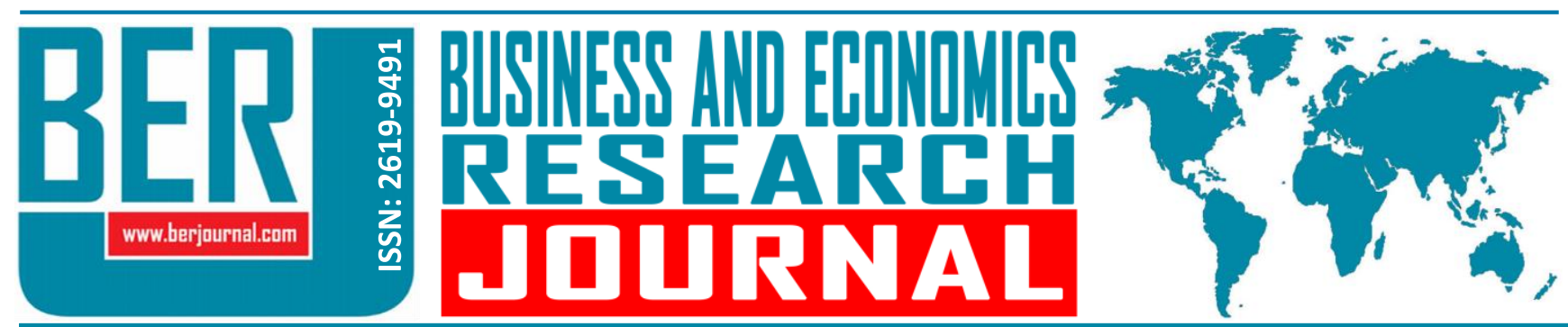

Business and Economics Research Journal Vol. 12, No.3, $2021 \quad$ pp. 509-522 doi: 10.20409/berj.2021.335

\title{
Forecasting of the U.S. Steel Prices with LVAR and VEC Models
}

\section{Kaveh A. Adli ${ }^{\mathrm{a}}$, Ugur Sener ${ }^{\mathrm{b}}$}

Abstract: Base metal prices, especially steel, play a significant role in industrial economics, making them worth knowing about future values. In most cases, we expect superior performance from multivariate forecasting models comparing univariate methods due to the involvement of explanatory variables in the system. Standard vector auto regressive model can only capture short-run dynamics because of the differencing process for non-stationary series that eliminates the possible long-run relationship. Instead, performing non-stationary series on levels through the vector auto-regressive framework does not suffers such loss. Moreover, the vector error correction model can define both short-term and long-run dynamics explicitly. These models can yield more robust forecasts in the mid-term and long-term by investigating short-run and long-run relationships simultaneously. The current study aims to perform an out-of-sample forecast for the United States steel prices index 18 months ahead using cointegrated variables. The results suggest that the non-stationary vector auto-regressive model outperforms the vector error correction model regarding mean absolute percentage error and root mean square error as forecast accuracy measures.

Keywords: Cointegration, Forecast, Steel, VAR, VEC

JEL: C22, C32, C53

$\begin{array}{ll}\text { Received } & : \text { 14 April } 2021 \\ \text { Revised } & : \text { 19 May } 2021 \\ \text { Accepted } & : \text { 24 June } 2021 \\ & \\ \text { Type } & \text { : Research }\end{array}$

\section{Introduction}

John Hicks defines the impact of the statistical revolution on economic studies through the middle of the $20^{\text {th }}$ century as the rise of econometrics (Hicks, 1956). Economic forecasts have become a broadly speaking subject along with the advancement of statistical methods. However, owing to uncertainty and unprecedented interventions in an economy, forecasting financial time series has become a challenging task for decades. Steel products, which are the most critical ferrous-based commodities, can be seen as the backbone of every country's development. According to the World Steel Association (2020), crude steel production was reached an enormous amount of 1.87 billion tons in 2019 . The economic state of a country is considerably related to steel consumption.

Since 2008, steel products have been traded in the commodity exchange markets with futures contracts, which have changed steel's role from a physical asset to a financial asset (Arık \& Mutlu, 2014). It has become a hedge to protect the investment against the economic fluctuations and profit-making means for the traders. Thus the art of forecasting can be a precious tool for mitigating the risk in commodity

a Istanbul Aydin University, Institute of Graduate Sciences, Business Administration (in English) Program, Istanbul, Turkiye, kaveh.adl@gmail.com (ORCID ID: 0000-0002-5549-3258)

b Asst. Prof., PhD., Istanbul Aydin University, Faculty of Economics and Administrative Sciences, Department of Business Management (in English), Istanbul, Turkiye, usener@aydin.edu.tr (ORCID ID: 0000-0001-5524-1707) 
exchange markets, and besides, forecasting the steel prices as a physical asset makes essential contributions to the policymakers at all levels.

The United States (U.S.) is considered a leading country in importing steel products with an approximate value of 27.1 million tonnes in 2019. Also, among the major crude steel producer countries, the U.S. takes fourth place after China, India, and Japan. The most important countries which export steel products to the U.S. are Canada, Brazil, Mexico, and South Korea (World Steel Association, 2020). Although various researches on the U.S. steel industry have been done in past years, still, lack of comprehensive academic research is felt in investigating the steel prices. With recent tariffs and limitations imposed on the steel products import from Canada, South America, and the European Union (EU), it is essential to interrogate steel prices and useful leading indicators in price changes. Concurrently, forecast models should be made to predict the price changes to mitigate economic instability risks.

The introduction of Vector Auto-Regressive (VAR) models by Sims (1980) dissolved multivariate forecasting's complexity due to the assumption of exogeneity. In this model, all variables can be treated as endogenous variables. Due to simultaneous equations for all variables in the system, which depend on lagged values, there is no need to forecast input variables separately with univariate models.

In this study, the non-stationary VAR and Vector Error Correction (VEC) models are used for forecasting purposes. For model validation, we use the out-of-sample (hold-out sample) forecast. As an indicator of steel prices, we use the Producer Price Index for steel mill products. The forecast horizon is selected as 18 months, considering future contracts' average duration in the New York Merchandise Exchange (NYMEX) and the London Metal Exchange (LME).

In section 2, the methodology for VAR, VEC models, and cointegration are explained. Section 3 is set to present the data and model specifications. Section 4 is designated for the forecast results and discussion. Subsequently, it is followed by section 5 , which is the conclusion.

\section{Literature Review}

Several papers have gone through commodity prices forecast models, yet few consider forecast models for steel prices. The dedicated literature on steel prices has investigated the price determination structure considerably more than practical forecasting models. Mancke (1968) and Grossman (1986) gave an insight into the U.S. steel industry using conventional regression analysis and raw materials cost, capacity utilization, imports and, industrial production index as input variables. Blecker (1989) applied a dynamic regression model to determine the U.S. steel prices by shipments dividends and major steel producer company's market shares in addition to previous works. Moreover, Liebman (2006), as the most comprehensive study for the U.S. steel price determination, brought in the steelworkers' wage, exchange rates and, China's steel demand as input variables as well as previous variables in the literature. Richardson (1999) assessed the effect of low-cost steel imports from Eastern-European countries on the European Community using regression analysis.

The global steel forecast model was tried by Malanichev and Vorobyev (2011) with multivariate regression using raw material costs and capacity utilization. In the research by Kapl and Müller (2010), the authors compared the efficiency of the autoregressive integrated moving averages (ARIMA) model with covariates versus multi-channel singular spectrum analysis (M-SSA). They concluded that the M-SSA model is more favorable in the generalization of the forecast. Chou (2013) went towards bivariate fuzzy time series analysis for forecasting long-term global steel prices with the bulk shipping prices as an explanatory variable, while $\mathrm{Wu}$ and Zhu (2012) adopted artificial neural network (ANN) for forecasting a week ahead with a univariate model for steel prices. The most recent attempt to forecasting steel prices made by Liu, Wang, Zhu, and Zhang (2015) using back propagation neural network (BPNN) with multivariate inputs. They used China's steel price index along with iron ore and coal prices index and the average monthly trading volume of the rebar steel as explanatory variables. As an attempt to price determination in Turkey, Akman (2016) looked into the effect of the EUR/USD exchange rate on the Turkish steel prices using the VAR model. Popescu, Nica, Stefanescu-Mihaila, and Lazaroiu (2016) consider the problematic effects of steel imports into 
the U.S., as job loss and declining production capacity resulted from low-cost imports from countries with aggressive export policy. Most recent works on steel prices focus on China's steel industry due to extraordinary economic growth. Kim and Lim (2019) investigated price discovery and a spillover effect in spot and futures markets using VEC and generalized autoregressive conditional heteroscedastic (GARCH) models. Their research concluded in the existence of the price discovery in all of the steel futures markets. They showed a spillover effect between spot and future market in wire rod, coking coal, coke, and silicomanganese. Another research has come from Cetin, Aksoy and Iseri (2019), which tried to forecast steel prices using the long short-term memory network model (LSTM). They used ten years' steel price data obtained from LME to forecast steel prices. Liu, Wang, Zhu, and Zhang (2015) worked on the impact of Chinese steel product prices. The proposed methodology for this work is the adaptive neuro-fuzzy inference system (ANFIS) which is the hybrid method from back propagation (BP) method and least square. Their results revealed that Asian countries have a greater impact on China's import market. Furthermore, sheet steel products have a significant effect on import and export markets.

As we search for reliable forecast models on base metals and specifically steel prices, we found very few academic resources with appropriate modeling aspects. There are few available academic papers for steel forecast models that are complex to implement in practice. In contrast, the models being used in practice are not established on a robust theoretical framework. Thus, this study aims to find a capable forecasting model for steel prices.

\section{The Methodology}

\subsection{Vector Autoregression Model}

VAR model, which has introduced by Sims (1980), is the expansion of the autoregressive model (AR) with the ability to enter more than one variable as endogenous variables to the model. In this system, each endogenous variable on the left side is affected by its own lags, as well as other endogenous variables lags on the right side by (P) lags. The mathematical expression of the reduced-form of the VAR (P) model is represented in equation (1).

$$
Z_{t}=\delta+\sum_{i=1}^{P} \Gamma_{\mathrm{i}} Z_{t-i}+\mu_{t}
$$

Where $\left(Z_{t}\right)$ is $(\mathrm{N} \times 1)$ vector of endogenous variables, $(\delta)$ is $(\mathrm{N} \times 1)$ intercept vector, $\left(\Gamma_{\mathrm{i}}\right)$ is $(\mathrm{N} \times \mathrm{N})$ coefficient matrix for the autoregressive process ( when: $i>0, \emptyset_{P} \neq 0$ ), and $\left(\mu_{t}\right)$ is $(N \times 1)$ vector of the white noise error term.

Commonly, the VAR model is estimated by the ordinary least squares (OLS). Accordingly, all assumptions about OLS are also applicable to the VAR model estimation process. However, for cointegrated time series, OLS estimation can handle the non-stationarity in variables and obtains consistent parameter estimation. For this reason, the differencing in variables is not needed as it eliminates the long-run dynamics in case of existence (Phillips \& Durlauf, 1986; West, 1988; Sims, Stock, \& Watson, 1990).

Selection of optimal lag length for VAR (P) system can be made by information criteria such as likelihood ratio (LR), Akaike's final prediction error (FPE), Akaike information criterion (AIC), Schwarz information criterion (SIC), or Bayesian information criterion (BIC), and, Hannan-Quinn information criterion (HQ). The optimal lag length selection is sensitive to the maximum lag length in the unrestricted VAR model. In the literature, 6 and 12 lag lengths are mostly suggested for monthly data.

Gredenhoff and Karlsson (1999) stated that AIC defines the lag length in VAR systems better than other information criteria. Alternatively, Lütkepohl (2005) suggested whenever the VAR model is used for forecasting purposes, the selection of optimal lag length is not a momentous task since the main objective is the improvement of forecast accuracy. 


\subsection{Cointegration}

According to Granger (1981), cointegration between two series is defined by proportional and equivalent movement in the long-run dynamics when the effect of lags (short-run relationship) is denied. In other words, when two or more variables are integrated of order $d$, there can be an underlying linear relationship in less order than $d$ between the variables, which is called cointegration (Engle \& Granger, 1987). As commonly in financial data, the variables are integrated of order one, where the cointegration relationship has to be a stationary process in case of existence.

Cointegration tests are used to reveal the evidence of underlying long-run economic equilibrium between the variables. Whereas the Engle and Granger (1987) test procedure only allows for one combination of cointegrated variables, with the Johansen and Juselius (1990) and Johansen's (1991) test procedure, it is possible to disclose more than one cointegrated relationships between $N$ time series with the integration order of $\mathrm{I}(1)$.

\subsection{Vector Error Correction Model}

Based on Engle and Granger (1987), the error correction term (ECT) shows the state of the departure (shock) from the long-run equilibrium in the antecedent period, which will be corrected in the subsequent period. The error correction model (ECM) can state both short-run and long-run dynamics in a single model. While the Engle and Granger (1987) method for ECM constitutes a single equation with a dependent variable and multiple independent variables, Johansen (1991) VEC model uses the VAR methodology to determine multiple cointegration combinations between the variables.

The standard VAR model is performed in differences to avoid non-stationarity. However, using differenced variables results in a misspecified model due to the data loss in the long run when the cointegration is present. In this situation, using unrestricted VAR in levels (LVAR) which is not suffers from misspecification, can be preferred (Engle \& Yoo, 1987). Using non-stationary variables in the VAR model with OLS estimation has raised concerns about the model's stability as coefficients are near the unit circle. Outcomes in Sims, Stock, and Watson (1990) and Toda and Phillips (1993) demonstrates a standard asymptotic distribution for regression coefficients in the LVAR model under the cointegration case for explanatory variables. Lutkepoh and Kratzig (2004) suggest that unlike LVAR models, which can indicate short-run and long-run relationships implicitly, VEC models can explicitly show cointegration relations. Although LVAR models can capture stochastic trends, most econometric books suggest avoiding using LVAR models in case of cointegration due to the proper coefficient estimation and advise to move on to VEC models. However, when the ultimate goal of the study is pure forecasting in practice, the LVAR model can yield promising results since the estimation of the coefficients are not as crucial as economic interpretation ( Fanchon \& Wendel, 1992; Clements \& Hendry, 1995; Hoffman \& Rasche, 1996; Suharsono, Aziza, \& Pramesti, 2017; Ajayi, 2019; Shang, Gang \& Cheng 2020).

Unlike the LVAR model, which is performed with variables in the level form, the VEC model should be performed with differenced variables to represent the short-run dynamics. The error correction term enters the equation to indicate the long-run dynamics. The mathematical representation of the VEC model is shown as equation (2).

$$
\Delta Z_{t}=\delta+\sum_{i=1}^{P-1} \Gamma_{\mathrm{i}} \Delta Z_{t-i}+\Pi_{\mathrm{y}_{\mathrm{t}-1}}+\mu_{t}
$$

Where $\left(\Delta Z_{t}\right)$ is $(\mathrm{N} \times 1)$ vector of first-differenced endogenous variables, $(\delta)$ is $(\mathrm{N} \times 1)$ intercept vector, $\left(\Gamma_{i}\right)$ is $(\mathrm{N} \times \mathrm{N})$ coefficient matrix for the autoregressive process or short-run dynamics, $\Pi$ is the coefficient matrix for error correction term, which shows the speed of adjustments for the shocks towards the long-run equilibrium. The $\left(\mu_{t}\right)$ is $(\mathrm{N} \times 1)$ vector of the white noise error term.

Optimal lag length selection criteria for the VAR (P) model are also applicable for the VEC model, whereas the lag length is reduced by one due to the differencing process. Thus, the $(P)$ lag order in the VAR model equates to the (P-1) lag order in the VEC model. 


\section{Data and Empirical Results}

\subsection{Data Description}

This study's gathered data are monthly data from January 2009 to June 2020 for a total of 138 months. Data from January 2009 to December 2018 (120 months) are used for model estimation, and from January 2019 to July 2020 (18 months) are used for model validation by the out-of-sample forecast.

All series are seasonally adjusted, which is mandatory for both LVAR and VEC models. For ease of use, all variables are indexed by January $2009=100$. Also, for stabilizing variance, natural logarithm (Ln) transformation is applied to all variables.

According to the U.S. Bureau of Labor Statistics (BLS), the Producer Price Indexes (PPI) are based on the probabilistic sample of selling prices for different sizes of establishments. Thus, it makes an appropriate indicator for market prices.

For the steel prices manifestation as target variable, we use the PPI of Steel Mill Products (ST) for the United States (U.S. Bureau of Labor Statistics 2020c). Steel mill products are consisting of total steel products, which are produced from molten steel into various shapes.

All explanatory variables are chosen with consideration to the existing literature on the United States steel industry as follow:

1. The PPI for Iron and Steel Scrap (SC) (U.S. Bureau of Labor Statistics, 2020b)

2. The global price of Iron Ore (IO) (US\$/ton) (International Monetary Fund, 2020b)

3. The global spot prices of Coal for Australia as the largest coal exporter in the world (CO) (US\$/ton) (International Monetary Fund, 2020a)

4. Import Price Index (End User) for Iron and Steel Mill Products (IM) (U.S. Bureau of Labor Statistics, 2020a) represents prices of iron and steel products that are imported into the U.S. from the rest of the world.

5. The Value of Manufacturers' New Orders for Iron and Steel Mills (NO) (M\$) (U.S. Census Bureau, 2020), which is the intention of manufactures to buy urgently or with future delivery; thus, it is the indicator of future demand.

We used almost the same theoretical structure in this study as Fanchon and Wendel (1992), Yuxian, Xiaoling and Songke (2014), and Ajayi (2019).

\subsection{Stationarity and Unit Root Test}

For variables to be modeled by VAR and, eventually, VEC models, the prerequisite is being first-order I(1) stationarity. Firstly, for testing stationarity, we used the Augmented Dickey-Fuller (ADF) test developed by Said and Dickey (1984), which is the extended version of the Dickey-Fuller (DF) test introduced by Dickey and Fuller (1979). The ADF test's null hypothesis favors the unit root existence, which is evidence of nonstationarity. The results of the ADF test for the variables are presented in Table 1.

Table 1. ADF Test Results for Variables

\begin{tabular}{lccccc}
\hline Variables & t-stat. & Prob. & $\Delta$ Variables & t-stat & Prob. \\
\hline LnST & 0.178783 & 0.7366 & $\Delta$ LnST & -5.518522 & 0.0000 \\
LnSC & 0.097150 & 0.7119 & $\Delta$ LnSC & -8.819061 & 0.0000 \\
LnIO & 0.314639 & 0.7752 & $\Delta$ LnIO & -8.868412 & 0.0000 \\
LnCO & -0.449434 & 0.5185 & $\Delta$ LnCO & -9.035877 & 0.0000 \\
LnIM & -0.203410 & 0.6113 & $\Delta$ LnIM & -5.395454 & 0.0000 \\
LnNO & 0.528214 & 0.8288 & $\Delta$ LnNO & -4.587397 & 0.0000
\end{tabular}

Notes: $\Delta=$ first difference, tested without intercept and trend. 
The ADF test results on variables before and after the first differencing process show evidence of possible integration of order 1 in all variables. Moreover, we test for the presence of the unit root in case of a structural break to ensure that the assumptions of our models are satisfied.

Financial time series often have one or more structural breaks during their life cycle. Structural breaks bring the ADF test validity under question since the ADF test cannot determine stationarity condition explicitly in case of structural breaks. However, Perron (1997) developed a test procedure that allows for structural breaks in both intercept and trend. In this paper, we perform the Perron test procedure by minimizing and maximizing the trend break t-statistics to find the breakpoint in data. The null hypothesis for the Perron test is the presence of unit root. The results are printed in Table 2.

Table 2. Perron Test Results for Variables

\begin{tabular}{lccccc}
\hline Variables & t-stat. & Prob. & $\Delta$ Variables & t-stat & Prob. \\
\hline LnST & -0.635632 & 0.9885 & $\Delta$ LnST & -5.717894 & 0.0000 \\
LnSC & -3.886775 & 0.1924 & $\Delta$ LnSC & -6.969274 & 0.0000 \\
LnIO & -2.209209 & 0.7534 & $\Delta$ LnIO & -8.989905 & 0.0000 \\
LnCO & -1.308185 & 0.9524 & $\Delta$ LnCO & -8.848781 & 0.0000 \\
LnIM & -0.765764 & 0.9842 & $\Delta$ LnIM & -5.451431 & 0.0000 \\
LnNO & -3.139833 & 0.4297 & $\Delta$ LnNO & -16.37397 & 0.0000 \\
\hline \multicolumn{5}{l}{ Notes: $\Delta=$ first difference, tested without intercept and trend. }
\end{tabular}

From the results of the Perron test, we can see the presence of unit root on the level form. Testing first differenced variables prove that our variables are the first order of integration considering structural breaks in the data. Thus, we can proceed with the VAR and VEC models.

\subsection{Granger Causality Test}

The Granger causality test procedure, which is proposed by Granger (1969), simply tests for the effectiveness of variable $X$ on the predictability of variable $Y$, assuming that changes in the $X$ 's past values affect the Y's future values. While the correlation between variables can be spurious and senseless, causality shows one variable's effectiveness in forecasting another. Also, the causality can be bi-directional in which the changes in the Y's past values also affect the variable X's future values.

The assumption for variables in the Granger causality procedure is to be stationary to avoid distortion in results, so the first differenced variables are used in the Granger causality analysis. The null hypothesis for the Granger causality test is that the variable $X$ does not granger cause variable $Y$. Thus, we investigate the causality of explanatory variables that are used to predict the LnST. The results of the Granger causality test for four lags are presented in Table 3.

Table 3. Granger Causality Test for LnST Variable

\begin{tabular}{lcccc}
\hline Null Hypothesis: & Lag 2 Prob. & Lag 3 Prob. & Lag 4 Prob. & Lag 5 Prob. \\
\hline$\Delta$ LnSC on $\Delta$ LnST & $2 . \times 10^{-11}$ & $5 . \times 10^{-10}$ & $2 . \times 10^{-9}$ & $2 . \times 10^{-8}$ \\
$\Delta$ LnST on $\Delta$ LnSC & 0.2526 & 0.0958 & 0.625 & 0.9626 \\
\hline$\Delta$ LnIO on $\Delta$ LnST & 0.0005 & 0.0025 & 0.0045 & 0.0060 \\
$\Delta$ LnST on $\Delta$ LnIO & 0.9516 & 0.6596 & 0.8141 & 0.5250 \\
\hline$\Delta$ LnCO on $\Delta$ LnST & 0.0027 & 0.0156 & 0.0179 & 0.0258 \\
$\Delta$ LnST on $\Delta$ LnCO & 0.9310 & 0.5856 & 0.3308 & 0.3664 \\
\hline$\Delta$ LnIM on $\Delta$ LnST & $3 . \times 10^{-5}$ & 0.0023 & 0.0133 & 0.0123 \\
$\Delta$ LnST on $\Delta$ LnIM & $2 . \times 10^{-7}$ & $7 . \times 10^{-6}$ & 0.0001 & 0.0003 \\
\hline$\Delta$ LnNO on $\Delta$ LnST & $4 . \times 10^{-5}$ & 0.0002 & $6 . \times 10^{-7}$ & $3 . \times 10^{-6}$ \\
$\Delta$ LnST on $\Delta$ LnNO & 0.2526 & 0.2556 & 0.0727 & 0.3546 \\
\hline
\end{tabular}

Notes: LnSC on LnST: that LnSC does not Granger Cause LnST. 
As seen from Table 3, there is a uni-directional causality running down from LnSC, LnIO, LnCO and, LnNO to LnST, which means they affect LnST separately, and by contrast, LnST has no Granger causality on none of them. For LnIM, there is a bi-directional causality, which means both variables Granger causes each other. since our aim in this paper is forecasting LnST, we concentrate on causalities from explanatory variables to the LnST. Following the fact that selected variables Granger cause LnST, we include all variables to forecast models.

The t-statistics and related $p$-values for coefficients are not reported for models as it is not essential to consider the significance of coefficients whenever the main objective is solely forecasting, especially in real-world conditions as long as the model forecasts well (Anderson, Burnham, \& Thompson, 2000; Armstrong, 2007; Kostenko \& Hyndman, 2008). In full system VAR models, it is expected to have insignificant coefficients due to multicollinearity between lags of variables. However, significance tests using $p$-values are thresholds that are contingent on sample sizes and unable to capture the actual level of the effect, which is subject to measurement (Kostenko \& Hyndman, 2008).

\subsection{LVAR Model}

For selecting the optimal lag length, the minimization of the AIC is considered after forming the unrestricted VAR model for a maximum length of 6 months. It is acquired that the optimal lag length of (4) is most appreciated for our data. The model statistics for the LnST equation in the LVAR model and information criteria for the whole system are presented in Table 4.

Table 4. LVAR (4) Estimation Results

\begin{tabular}{|c|c|c|c|c|}
\hline \multicolumn{5}{|c|}{ Full LVAR model Statistics: } \\
\hline \multicolumn{2}{|c|}{ AIC: -23.51084} & \multicolumn{2}{|c|}{ SCl: -19.95016 } & No. of Coefficients: 150 \\
\hline \multicolumn{5}{|c|}{ LnST Equation: } \\
\hline $\mathrm{R}^{2}:$ & 0.991742 & AIC: & -6.211192 & \\
\hline SSE: & 0.008857 & $\mathrm{SCl}:$ & -5.617746 & \\
\hline F-statistic: & 455.3759 & & & \\
\hline
\end{tabular}

To investigation the cointegration relationship among variables, the Johansen test procedure is used in this study. The process uses Trace and Maximum Eigenvalue test approaches with the null hypothesis that there is no cointegration between variables for both of them. However, there is a difference between these two approaches in the alternate hypothesis. The Trace test approach is more desirable when it is expected to have more than one cointegration combination among the variables ( Lütkepohl, Saikkonen, \& Trenkler, 2001; Cheung \& Lai, 2009).

Here, the Johansen test is performed considering intercept in the cointegration equation and no trend in variables. The trace test statistics and related $p$-values for the cointegration rank with the optimal lag length of (3), required to form the VEC model, are reported in Table 5.

Table 5. Johansen Cointegration test Results for Lag (3)

\begin{tabular}{lcc}
\hline No. of Cointegrations & Trace Stat. & Prob. \\
\hline None* & 139.9078 & 0.0000 \\
At most $1^{*}$ & 76.62493 & 0.0129 \\
At most 2 & 43.70409 & 0.1163 \\
At most 3 & 24.75459 & 0.1704 \\
At most 4 & 8.470328 & 0.4166 \\
At most 5 & 0.292014 & 0.5889 \\
\hline Notes: ${ }^{*}=5 \%$ significant. & &
\end{tabular}


The result of the Johansen test confirms the evidence of two underlying cointegration vectors. Thus, two combinations of the variables exist as a long-run equilibrium. Shoesmith (1995) pointed out some problems with multiple cointegration vectors when the underlying relationship is not originated from the framework of economic theory. Thus, defining the proper cointegration equation with consideration to logically expected results is desirable. Nevertheless, including the cointegration equation in the model, even if not relied on economic theory, may increase the forecast accuracy (Shoesmith, 1995). To represent both short-run and long-run relationships between the variables separately, the VEC model is estimated.

\subsection{VEC Model}

The lag length selected from the unrestricted VAR model is reduced by one lag to VEC (3) due to the first differencing process. The result of VEC (3) model information criteria with two cointegration equations and the model statistics for the LnST equation is reported in Table 6.

Table 6. VEC (3) Estimation Results

\begin{tabular}{|c|c|c|c|c|}
\hline \multicolumn{5}{|c|}{ Full VECM Statistics: } \\
\hline \multicolumn{2}{|c|}{ AIC: -23.34098} & \multicolumn{2}{|c|}{ SCl: -20.06515} & No. of Coefficients: 138 \\
\hline \multicolumn{5}{|c|}{ LnST Equation: } \\
\hline$R^{2}:$ & 0.742321 & AIC: & -6.175226 & \\
\hline SSE: & 0.009837 & $\mathrm{SCl}:$ & -5.676732 & \\
\hline F-statistic: & 13.68378 & & & \\
\hline
\end{tabular}

The error correction terms (ECT) for VEC model are shown in equations (3) and (4).

$$
\begin{aligned}
& \Pi_{y_{t-1}}=-0.135\left(\operatorname{LnST}_{t-1}+0.026 \operatorname{LnIO}_{t-1}-0.094 \operatorname{LnCO}_{t-1}-0.687 \operatorname{LnIM}_{t-1}+\right. \\
& \left.0.114 \operatorname{LnN} O_{t-1}\right) \\
& \Pi_{\mathrm{y}_{\mathrm{t}-1}}=-0.068\left(\operatorname{LnSC}_{t-1}-0.122 \operatorname{LnIO}_{t-1}+0.067 \operatorname{LnCO}_{t-1}-0.485 \operatorname{LnIM}_{t-1}-\right. \\
& \left.1.03 \operatorname{LnNO}_{t-1}\right)
\end{aligned}
$$

In the normalized cointegration equation with constraints on LnST and LnSC, all the signs for coefficients are consistent with the economic theory reviewed in the literature. According to Shoesmith (1995a), the interpretation of signs in the cointegration equation is opposite, where the positive sign represents an inverse relationship; the negative sign represents a direct relationship. The LnIM has a direct relationship with LnST in both equations. For the $\mathrm{LnNO}$, LnIO, and $\mathrm{LnCO}$, there are different signs in each equation. They correct each other in favor of a direct relationship, which means an increase in each variable, results in an increase in LnST in the long run.

Inherently, the LnNO indicates the growing demand, which can cause an increase in LnST. For the LnIM, There is robust economic proof that it affects the LnST directly (Liebman, 2006). Also, LnCO and LnIO, as raw materials for steel production, are expected to have a direct and positive effect on LnST.

It is worth noting that the sign of ECT is negative in both equations, which refers to the convergence of the target variable (LnST) to the long-run equilibrium at the speeds of $13.5 \%$ and $6.8 \%$ per month.

\subsection{Diagnosis Tests}

The residuals are checked for assumptions that apply to the OLS estimations. The Breusch-Godfrey LM test is applied to investigate the serial correlation in residuals. The null hypothesis is in favor of no autocorrelations in residuals. The Breusch-Pagan-Godfrey test is used to present heteroscedasticity in residuals, where the null hypothesis is homoscedasticity. The diagnosis test results for each model are arranged in Table 7. 
Table 7. Diagnosis Tests Results

\begin{tabular}{lll}
\hline Models: & LVAR & \multicolumn{2}{c}{ VEC } \\
\hline Test & \multicolumn{2}{c}{$P$-Values } \\
\hline Serial correlation for five lags & 0.1293 & 0.3511 \\
heteroscedasticity & 0.2415 & 0.0750 \\
\hline
\end{tabular}

Notes: ${ }^{*}=5 \%, * *=1 \%$ significant.

As observed from the diagnostic test result, there are no serial correlation and heteroscedasticity evidence in the residuals, and thus the models are efficiently fitted to the data.

\subsection{Impulse Response Function (IRF)}

The impulse response function (IRF) determines the reaction of one variable across time to alteration of another variable(s) at various time periods ( Pesaran \& Shin, 1998; Ederer, Heumesser, \& Staritz, 2016). The recognition of IRF resulted from diagonal one standard deviation of the residuals for impulses. The IRF graphs for the LVAR and VEC models within 36 periods are shown in Figure 1 and Figure 2.

Figure 1. The IRF for LVAR Model

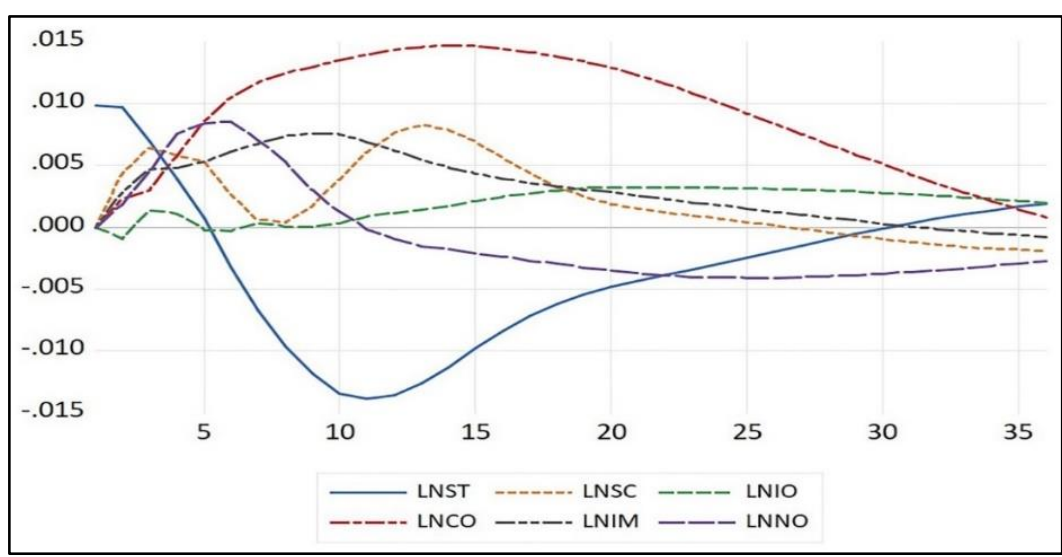

Figure 2. The IRF for VEC Model

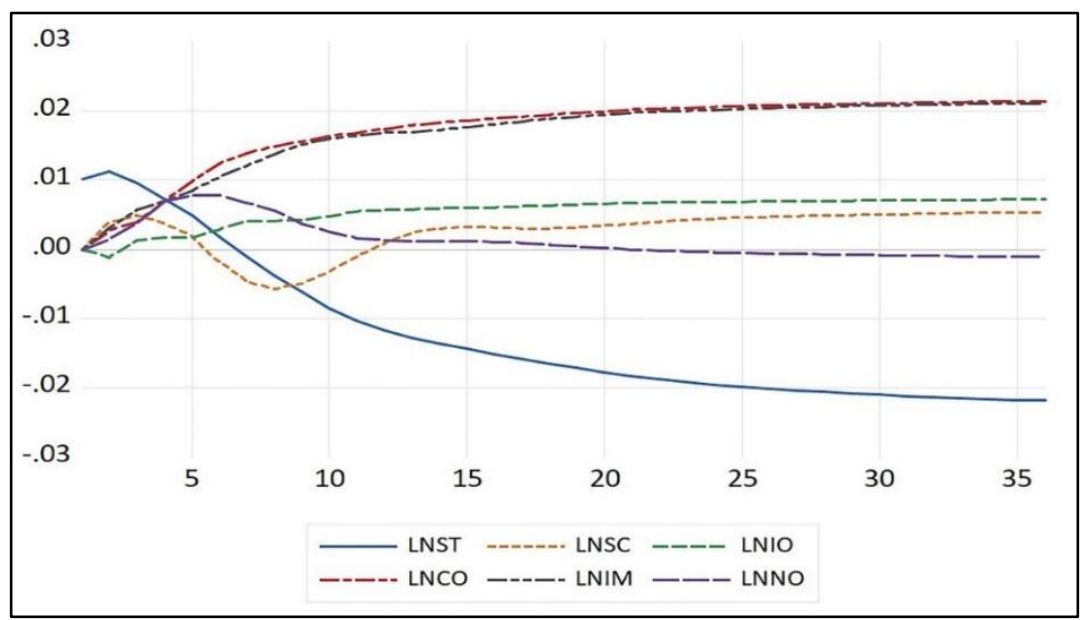


The IRF for LVAR and VEC models is similar in the short run. For a few first periods, all variables' impulses, except LnIO, have an increasing impact on the response of LnST, which then LnST's own lags have a decreasing effect after the 2 nd period in both models. The LnSC tends to have a negative effect after six periods in the VEC model and not positive until the $12^{\text {th }}$ period, which afterward tends to have a positive effect. While, in the VEC model, after approximately 25 periods, variables' impulses on the LnST responses tend to their long-run position, in the LVAR model, responses seem to dump the impulses' effects. The similarity among LVAR and VEC models short-run IRF suggests consistent results with Naka and Tufte's (1997) analysis.

\section{Forecasting Results and Discussion}

Monthly out-of-sample forecasts from January 2019 to June 2020 (18 months) for LVAR and VEC models, along with the forecast accuracy measures, are reported in Figure 3 and Table 8. For comparing forecast accuracy in models, the mean absolute error (MAE), mean absolute percentage error (MAPE), and root mean square error (RMSE) are used considering the literature. The RMSE is superior to MAE, where the model's residuals are normally distributed (Chai and Draxler 2014). Armstrong and Collopy (1992) conclude that using RMSE is not appropriate to compare the forecast accuracy of the models that use different modeling methods due to low authenticity. The MAPE is the most common error measurement for forecasting models. According to Hyndman and Koehler (2006), for the data that are positive and relatively large to zero, using MAPE is suitable given the inherent clarity for the comparison purpose. Çuhadar (2020) stated the benefits of using the MAPE measure in comparing different model and interpretation feasibility without considering size of the sample. According to Lewis (1982) the MAPE value under $10 \%$ demonstrate high degree of accuracy for the model, while above $50 \%$ value showed a poor performance.

Table 8. Forecast Accuracy Measures for LnST

\begin{tabular}{lcc}
\hline & LVAR & VEC \\
\hline RMSE & 0.023766 & 0.047488 \\
\hline MAPE & $0.423052 \%$ & $0.804208 \%$ \\
\hline Notes: MAPE in Percentage, RMSE: Same level as variables.
\end{tabular}

Notes: MAPE in Percentage, RMSE: Same level as variables.

Figure 3. Forecast Results for LVAR and VEC Models

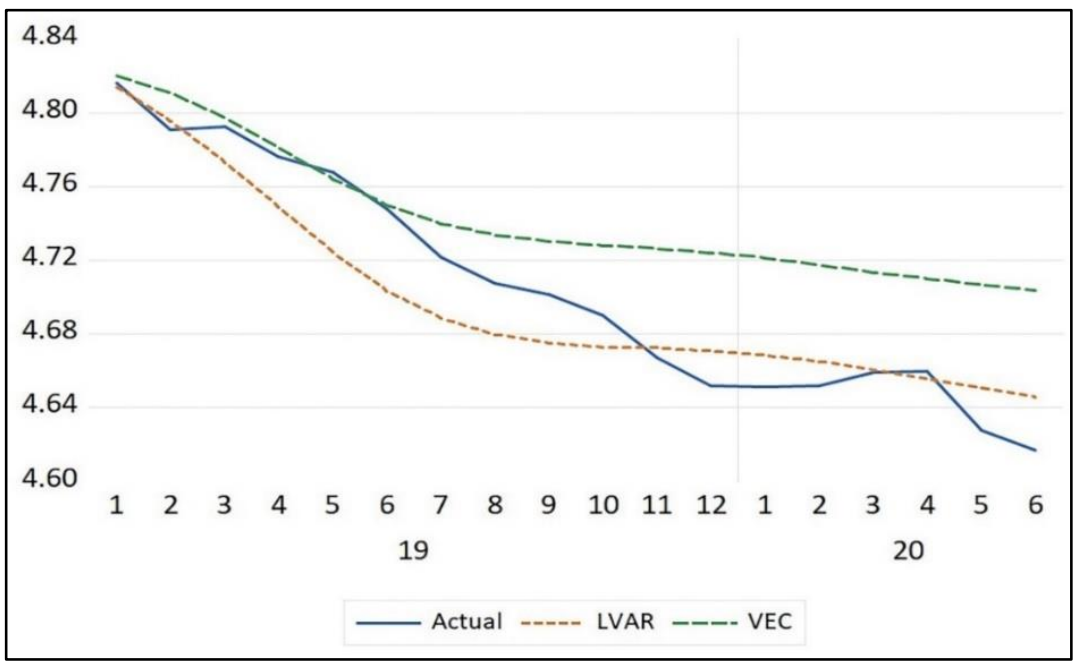


While both models perform accurate results, comparing the results of the LVAR and VEC models reveal that the LVAR model yields smaller MAPE and RMSE for 18 months forecast. The findings seem to contradict Engle and Yoo's (1987) results, which suggest the superiority of Engle-Granger error correction models in the long-term forecast horizon over LVAR models. However, Hoffman and Rasche (1996) and Clements and Hendry (1995) showed mixed outcomes about the performance of VEC over LVAR models, which latter study presented moderate superiority of LVAR compare to VEC models. Fanchon and Wendel (1992) and Ajayi (2019) obtained the same outcome, in which LVAR outperforms the VEC model both in short and long-run forecasts. They concluded that one possible reason is that the time-span of short-run dynamics might be influenced by lag length.

\section{Conclusion}

To forecast the producer price index for steel mill products in the U.S., we used leading indicators as iron and steel scrap PPI, global price of iron ore, global price of coal, import price index for iron and steel products, and the value of manufacturers' new orders for iron and steel mills. The VAR in levels and VEC models are used in this study. Where the VAR model in differences eliminates long-run relationships in case of existence, performing the VAR model in levels does not suffers from this issue. However, most of the literature advises using the VEC model to investigate and forecast cointegrated data. we derive that our data are non-stationary and integrated of order 1 using ADF test for stationarity and unit root. The Granger causality test demonstrates the significant causal relationships among the variables of interest. We perform the LVAR model by selecting optimal lag length using AIC, considering the absence of serial correlation in errors. We find the evidence of two cointegration vectors from the Johansen cointegration test. Performing of the VEC model approved reveals the short-run and long-run relationships explicitly. Our results show the better forecasting performance of the LVAR model rather than VEC regarding MAPE and RMSE accuracy measures. However, these results should be noticed suspiciously since the forecast accuracy depends on several items. Variables' time span, model specifications, and forecast horizon are major determinants to select the suitable model to forecast steel prices.

The current study results show that a simple VAR model can be adequately used to forecast shortterm and mid-term horizons with confidence in practice. On the other hand, this is applicable when the goal is pure forecasting since the application of the VAR model in cointegrated data for determination purposes is not appreciate due to mixed interpretation of both short-run and long-run relationships.

Future studies can be done more comprehensively by examining different indicators, forecast horizons, and model settings. Another study is possible through using data from another region which in this study, we have limited sources for our data. Also, future models can be done by hybrid models using ANN algorithms and econometric models to achieve more reliable results.

\section{Declarations and Disclosures}

Ethical Responsibilities of Authors: The authors of this article confirm that their work complies with the principles of research and publication ethics.

Conflicts of Interest: No potential conflict of interest was reported by the authors.

Funding: The authors received no financial support for the preparation and/or publication of this article.

Author Contributions: The authors confirm contribution to the article as follows: Conceptualization and design, K. A. Adli and U. Sener; data collection, K. A. Adli and U. Sener; analysis of data and interpretation of results, K. A. Adli and U. Sener; writing the first draft of the manuscript, K. A. Adli; review and editing, K. A. Adli and U. Sener. The manuscript/article was read and approved by all the authors, and all authors accepted responsibility for their article.

Plagiarism Checking: This article was screened for potential plagiarism using a plagiarism screening program. 


\section{References}

Ajayi, O. V. (2019). Comparing multivariate models' forecasts of inflation for BRICS and OPEC countries. Business, Management and Education, 17(2), 152-172.

Akman, E. (2016). Impacts of Euro/USD volatility on steel prices of Turkey. ECOFORUM, 5(1), 133-139.

Anderson, D. R., Kenneth, P. B., \& William, L. T. (2000). Null hypothesis testing: Problems, prevalence, and an alternative. The Journal of Wildlife Management, 64(4), 912-923

Arık, E., \& Mutlu, E. (2014). Chinese Steel market in the post-futures period. Resources Policy, 42(2014), 10-17.

Armstrong, J. S., \& Collopy, F. (1992). Error measures for generalizing about forecasting methods: Empirical comparisons. International Journal of Forecasting, 8(1), 69-80.

Armstrong, J. S. (2007). Significance tests harm progress in forecasting. International Journal of Forecasting, 23(2), 321327.

Blecker, R. A. (1989). Markup pricing, import competition, and the decline of the American steel industry. Journal of Post Keynesian Economics, 12(1), 70-87.

Cetin, K., Aksoy, S., \& Iseri, I. (2019). Steel Price forcasting using long short-term memory network model. 4th International Conference on Computer Science and Engineering (UBMK), 612-17.

Chai, T., \& Draxler, R. R. (2014). Root mean square error (RMSE) or mean absolute error (MAE)? - Arguments against avoiding RMSE in the literature. Geoscientific Model Development, 7(3), 1247-50.

Cheung, Y. W., \& Lai, K. S. (2009). Finite-sample sizes of Johansen's likelihood ratio tests for cointegration. Oxford Bulletin of Economics and Statistics, 55(3), 313-328.

Chou, M. T. (2013). An application of fuzzy time series: A long range forecasting method in the Global Steel Price Index forecast. Review of Economics \& Finance, 3, 90-98.

Clements, M. P., \& Hendry, D. F. (1995). Forecasting in cointegrated systems. Journal of Applied Econometrics, 10(2), 127-146.

Dickey, D. A., \& Fuller, W. A. (1979). Distribution of the estimators for autoregressive time series with a unit root. Journal of the American Statistical Association, 74(366), 427-431.

Çuhadar, M. (2020). A comparative study on modelling and forecasting tourism revenues: The case of Turkey. Advances in Hospitality and Tourism Research (AHTR), 8(2), 235-255.

Ederer, S., Heumesser, C., \& Staritz, C. (2016). Financialization and commodity prices: An empirical analysis for coffee, cotton, wheat and oil. International Review of Applied Economics, 30(4), 462-487.

Engle, R. F., \& Granger, C. W. J. (1987). Co-integration and error correction: Representation, estimation, and testing. Econometrica, 55(2), 251-276.

Engle, R. F., \& Yoo, B. S. (1987). Forecasting and testing in co-integrated systems. Journal of Econometrics, 35(1), 143159.

Fanchon, P., \& Wendel, J. (1992). Estimating VAR models under non-stationarity and cointegration: Alternative approaches for forecasting cattle prices. Applied Economics, 24(2), 207-217.

Granger, C. W. J. (1981). Some properties of time series data and their use in econometric model specification. Journal of Econometrics, 16(1), 121-130.

Granger, C. W. J. (1969). Investigating causal relations by econometric models and cross-spectral methods. Econometrica, 37(3), 424-438.

Gredenhoff, M., \& Karlsson, S. (1999). Lag-length selection in VAR-models using equal and unequal lag-length procedures. Computational Statistics, 14(2), 171-187.

Grossman, G. M. (1986). Imports as a cause of injury: The case of the U.S. steel industry. Journal of International Economics, 20(3-4), 201-223.

Hicks, J. (1956). A revision of demand theory. New York: Oxford University Press.

Hoffman, D. L., \& Rasche, R. H. (1996). Assessing forecast performance in a cointegrated system. Journal of Applied Econometrics, 11(5), 495-517.

Hyndman, R. J., \& Koehler, A. B. (2006). Another look at measures of forecast accuracy. International Journal of Forecasting, 22(4), 679-688.

International Monetary Fund, (2020a). Global price of coal, Australia (PCOALAUUSDM) | FRED | St. Louis Fed. Retrieved October 16, 2020, from https://fred.stlouisfed.org/series/PCOALAUUSDM 
International Monetary Fund, (2020b). Global Price of Iron Ore (PIORECRUSDM) | FRED | St. Louis Fed. Retrieved October 16, 2020, from https://fred.stlouisfed.org/series/PIORECRUSDM

Johansen, S. (1991). Estimation and hypothesis testing of cointegration vectors in gaussian vector autoregressive models. Econometrica, 59(6), 1551-1580.

Johansen, S., \& Juselius, K. (2009). Maximum likelihood estimation and inference on cointegration - with applications to the demand for money. Oxford Bulletin of Economics and Statistics, 52(2), 169-210.

Kapl, M., \& Müller, W. G. (2010). Prediction of steel prices: A comparison between a conventional regression model and MSSA. Statistics and Its Interface, 3(3), 369-75.

Kim, K., \& Lim, S. (2019). Price Discovery and volatility spillover in spot and futures markets: Evidences from steel-related commodities in China. Applied Economics Letters, 26(5), 351-357.

Kostenko, A. V., \& Hyndman, R. J. (2008). Forecasting without significance tests?. Australia: Monash University Manuscript.

Lewis, C. D. (1982). Industrial and business forecasting methods: A practical guide to exponential smoothing and curve fitting. Butterworth Scientific Press.

Liebman, B. H. (2006). Safeguards, china, and the price of steel. Review of World Economics, 142(2), 354-73.

Liu, Y., Li, H., Guan, J., Feng, S., \& Guo, S. (2019). The impact of Chinese steel product prices based on the midstream industry chain. Resources Policy, 63(June), 101415.

Liu, Z., Wang, Y., Zhu, S., \& Zhang, B. (2015). Steel prices index prediction in China based on BP neural network. 4th International Conference on Logistics, Informatics and Service Science, 603-608

Lütkepohl, H., \& Kratzig, M. (2004). Applied time series econometrics. Cambridge University Press.

Lütkepohl, H. (2005). VAR order selection and checking the model adequacy. In New introduction to multiple time series analysis (pp. 146-57). Berlin, Heidelberg: Springer Berlin Heidelberg.

Lütkepohl, H., Saikkonen, P., \& Trenkler, C. (2001). Maximum eigenvalue versus trace tests for the cointegrating rank of a var process. The Econometrics Journal, 4(2), 287-310.

Malanichev, A. G., \& Vorobyev, P. V. (2011). Forecast of global steel prices. Studies on Russian Economic Development, 22(3), 304-311.

Mancke, R. (1968). The determinants of steel prices in the U.S.: 1947-65. The Journal of Industrial Economics, 16(2), 147160.

Naka, A., \& Tufte, D. (1997). Examining impulse response functions in cointegrated systems. Applied Economics, 29(12), 1593-1603.

Pesaran, H. H., \& Shin, Y. (1998). Generalized impulse response analysis in linear multivariate models. Economics Letters, 58(1), 17-29.

Perron, P. (1997). Further evidence on breaking trend functions in macroeconomic variables. Journal of Econometrics, 80(2), 355-385.

Phillips, P. C. B., \& Durlauf, S. N. (1986). Multiple time series regression with integrated processes. The Review of Economic Studies, 53(4), 473-495.

Popescu, N., Stefanescu-Mihaila, R. O., \& Lazaroiu, G. (2016). The United States (U.S.) steel import crisis and the global production overcapacity till 2016. Metalurgija, 55(3), 538-540.

Richardson, P. K. (1999). EC steel prices and imports: Impact of imports from Eastern Europe. Journal of Product \& Brand Management, 8(5), 443-454.

Said, S. E., \& Dickey, D. A. (1984). Testing for unit roots in autoregressive-moving average models of unknown order. Biometrika, 71(3), 599-607.

Shang, D., Gang, D., \& Cheng, B. (2020). Dynamics of integration between Chinese and international waste paper markets. Journal of Sustainable Forestry, 39(5), 433-444.

Shoesmith, G. L. (1995). Long-term forecasting of noncointegrated and cointegrated regional and national models. Journal of Regional Science, 35(1), 43-64.

Sims, C. A. (1980). Macroeconomics and reality. Econometrica, 48(1), 1-48.

Sims, C. A., Stock, J. H., \& Watson, M. W. (1990). Inference in linear time series models with some unit roots. Econometrica, 58(1), 113-144. 
Suharsono, A., Aziza, A., \& Pramesti, W. (2017). Comparison of vector autoregressive (VAR) and vector error correction models (VECM) for Index of ASEAN stock price. AIP Conference Proceedings.

Toda, H. Y., \& Phillips, P. C. B. (1993). Vector autoregressions and causality. Econometrica, 61(6), 1367-1393.

U.S. Bureau of Labor Statistics, (2020a). Import Price Index (End Use): Iron and Steel Mill Products (IR141) | FRED | St. Louis Fed. Retrieved October 16, 2020, from https://fred.stlouisfed.org/series/IR141

U.S. Bureau of Labor Statistics, (2020b). Producer Price Index by Commodity: Metals and Metal Products: Iron and Steel Scrap (WPU1012) | FRED | St. Louis Fed. Retrieved October 16, 2020, from https://fred.stlouisfed.org/series/WPU1012

U.S. Bureau of Labor Statistics, (2020c). Producer Price Index by Commodity: Metals and Metal Products: Steel Mill Products (WPU1017) | FRED | St. Louis Fed. Retrieved October 16, 2020, from https://fred.stlouisfed.org/series/WPU1017

U.S. Census Bureau, (2020). Manufacturers' New Orders: Iron and Steel Mills and Ferroalloy and Steel Product Manufacturing (A31ANO) | FRED | St. Louis Fed. Retrieved October 16, 2020 from https://fred.stlouisfed.org/series/A31ANO

West, K. D. (1988). Asymptotic normality, when regressors have a unit root. Econometrica, 56(6), 1397-1417.

World Steel Association, (2020). World Steel in Figures.

Wu, B. \& Zhu, Q. (2012). Week-ahead price forecasting for steel market based on RBF NN and ASW. IEEE International Conference on Computer Science and Automation Engineering, (3), 729-732

Yuxian, F., Xiaoling, Y., \& Songke, H. (2014). Electricity investment and economic growth in China: A demonstration and a forecast based on the VAR model. Ekonomski Horizonti, 16(2), 81-96. 